\title{
The Implementation of Coping Strategy and Social Support to Reduce Work-Family Conflict on Women's Employee
}

\author{
Nadiarani Anindita ${ }^{1}$, Elia Daryati ${ }^{2}$, Rika Rianti Sari ${ }^{3}$ \\ Polytechnic of STIA LAN Bandung, Indonesia \\ \{nadiarani.anindita@poltek.stialanbandung.ac.id¹, eliadaryati1965@gmail.com², \\ rriantisari31@gmail.com ${ }^{3}$ \}
}

\begin{abstract}
This study examines the work-family conflict from the women's employee perspective, especially with long working hours related to the flexible time of working from home. This study also explains how the implementation of coping strategies and social support to help the women's employees reduce the work-family conflict from both roles. Eight informants were chosen based on purposive sampling. Analysis of in-depth interviews revealed that the informants experienced conflict from the long hour time spent for work and fulfilling family/personal life. Recommendations have been proposed based on informants coping strategies such as family segmentation, social support, especially from family or spouse, open communication, and positive work-family culture.
\end{abstract}

Keywords: work-family conflict; coping strategy; social support; women's employee

\section{Introduction}

Since the pandemic of the Covid 19 outbreak affected many countries worldwide, it has also changed many ways of living, including work life. The workers' stress level also increases during this challenging time because they face so many difficulties to do their job accordingly with different work systems. Governments across the world have implemented their own strategies to stop the spread of the virus, including the Indonesia Government. The change of work system from the conventional work from office is changing into work from home, significantly when the rate of people affected by this virus increases.

The workers' stress level also increases during this challenging time because they face so many difficulties to do their job accordingly with different work systems. Even though flexible working arrangements have been an issue for a long time, few organizations or companies have already used that, especially in Indonesia. When the pandemic comes, they have to adapt to this whether they are ready or not. The sudden change brings much potential conflict to the workers, especially women's employees, that is because the women have other roles at home as a mother and wife. This is perhaps due to their social and cultural obligations as the family's caretaker $[1]$.

The number of children owned by families in today's modern era, where the number is much less than in the past, is also indicated as the cause of women being able to share their focus not only on taking care of children but also for work. The increasing number of working women and couples who have dual careers professionally has resulted in the increase number 
of conflicts between family and work responsibilities in the literature on organizational behavior.

Married people experienced more work-family conflict than those not married. Furthermore, people who have children will experience much more work-family conflict than those who do not. Likewise, if the role at work is too heavy, it will trigger work-family conflict. Job demands are related to the pressure from excessive workloads and deadlines or deadlines for work to be completed. The great responsibility held in one role can affect the emergence of work-family conflict [1].

Both roles between work and family now take place in people's homes. Based on the workfamily conflict theories, there are three forms of conflict associated with the dilemma of women's employees. First, time-based conflict comes when the amount of time to serve one domain cannot be used to satisfy other roles, including the time management, resources, and abilities from work and domestic roles. Second, strain-based conflict is a conflict that arises when the emerge of stress or emotional state created by one role results in difficulties for an individual to accomplish another role expectancy.

A mother who works for a long hour in one day, for instance, might feel exhausted, and it is almost impossible for her to sit with her child comfortably in order to finish the family chores. Third, behavior-based conflict, arises when the behavior on one particular domain is not matched with behavior on another role. The mismatch in individual behavior at work and at home due to disparities in a professional woman's behavioral rules is typically difficult to change between the positions she performs with each other [1].

To overcome stressful or difficult situations, individuals make appraisals with particular coping strategies that may vary across individuals based on their experiences and dispositional characteristics. Based on the description above, the research question guiding this work is what is the best coping strategy to reduce work-family conflict on womens' employees

\section{Literature Review}

\subsection{Work-Family Conflict}

Work-family conflict (WFC) is a conflict of an individual's inter-role that arises due to pressure from the conflict of work and family roles [1]. The mismatch is indicated by participation in work roles with more time and attention being devoted than participation in family roles and vice versa. Work-family conflict happens when an individual has a long working hour or immensely amount of works. The amount of excessive time and effort used to work may decrease the time and energy that can be done to carry out family activities [2].

Greenhaus and Beutell [1] found that married people experienced greater work-family conflict than those who were not married. Furthermore, it is estimated that people who have children will experience a greater work-family conflict than those who do not have children. Likewise, if the role at work is felt too heavy, it will trigger work-family conflict. Job demands are related to the coercion that comes from immensely workloads or work deadlines. The great responsibility that is held in one role can affect the emergence of work-family conflict.

The work-family conflict may vary from different causes where forms of conflict are made. The two most common types of conflict are time-based conflict and strain-based work-family conflict. The main idea of time-based conflict arises when the time consumed to one role in one domain (work or family domain) results in too little time to participate in the other domain. Strain-based conflict happens when strain in one domain affects the acceptable performance of role behaviors in another domain or role [1]. 


\subsection{Coping Strategy}

The term of coping is always associated with stress or problems in the individual's life. Coping occurred based on the reality that individuals have to manage their problems to alleviate their stress. Coping enables individuals to handle stressful situations by developing techniques and strategies to deal with [3]. Lazarus described coping into cognitive and behavioral attempts to deal with internal or external appraised demands and constantly evolving based on the individual's situation appraisal [4].

There are two prominent kinds of coping: problem-focused coping and emotion-focused coping. Problem-focused coping includes strategies, either externally or internally. External directed coping strategies require altering the condition or situation in the environment to minimize stress on an individual's life. Internal directed coping imply the efforts by individuals to evaluate more about their behaviors, attitudes, knowledge, and skills in managing a difficult situation [5]. Emotion-focused coping describe as the emotional response or strategies to deal with a stressful situation. Emotion-focused coping is usually used when a person feels that the situation is beyond their control [6]. Problem-focused coping tends to be used when individuals feel they can manage and control the situation or do something about it. On the other hand, emotion-focused coping tends to dominate when individuals feel that the situation is outside their control [6].

When dealing with a very hard or stressful event, people can also use both forms of coping. Craver on his research concludes many types of coping strategies categorized as either problemfocused or emotion-focused coping strategies. How an individuals manage their problem can be seen from the type of coping strategies. Problem-focused coping strategies include planning as the effort to think through and figure out the necessary steps to answer the problem. Another type is active coping, implying that workers may actively deal with a demanding or stressful event. Suppression of competing activities or situations includes setting aside other activities or situations that may diminish from focusing on the demanding event. Seeking social support is another instrumental strategy to deal with the source of stress [7].

Another form of coping strategy that focuses on and venting their feelings or emotions is called emotion-focused coping. Individuals can relieve their distress using this coping strategy to be helpful and functional; on the other hand, focusing on the source of stress may influence people from actively engage in problem-solving. Seeking emotional support as empathy, encouragement, and understanding from social networks is part of seeking reason as a coping strategy.

Positive appraisal from positive reinterpretation and growth, help individual to reevaluate the events with a better construct of mind that may lead to problem-solving actively. Denial as a coping strategy, make the individual tends to think not to accept the existence of the stressor or situations around it. Dysfunctional coping includes behavior disconnection, where individuals try to change the goal to avoid dealing with the stressor. In dysfunctional coping, individuals may try to make themselves distracted by doing another activity such as socializing with the other and sleeping [7].

\subsection{Social Support}

Social support is described as interchange resources between at least two persons to help the individual who receives the support. Social support can include emotional support such as care, empathy, trust, and love; instrumental support includes real support in money, time, and energy; appraisal support (using the information to re-evaluate situations); informational support through information, advice, and suggestions [8]. 
Social support reduces work-family conflict directly or through changing the role conflict and role ambiguity as the impact of stressors that lead to work-family conflict. Social support may decrease work-family conflict from the work domain by impacting conflict from work role, time demands, and role ambiguity. Social support can also scale down the severity of family role conflict from the home domain by reducing family time demands, and family role ambiguity, which in turn reducing work-family conflict [9]. Another study, Thomas and Ganster (1995) found that receiving support from the supervisor minimizes work-family conflict both directly and indirectly through the increased sense of control over the areas of two domains from work and family [10].

\section{Methods}

This study was conducted to explore informants' experience regarding work-family conflict felt by women's employees during this pandemic time. Based on the phenomenon to be studied, the researcher uses the basis of the social constructivist worldview because there is an assumption that individuals have to understand the world in which they live and work. Individuals develop a subjective understanding of the experience which usually leads to a particular object or thing [11]. The data collection process was carried out by conducting interviews with informants so that informants could share their experiences and views. Understanding is obtained from a person's interpretation of the experience and the environment.

The research method used in this study is a qualitative research method because it is considered the most suitable for revealing phenomena based on the experiences of informants regarding work-family conflict felt by women. Convenience sampling was used; there were eight informants who participated in this study. The participants were individuals employed in the same private organizations, have more than five years of experience working, have a kid at the primary school level, and are willing to be interviewed. Data were collected with an in-depth interview, some was collected online using zoom meetings or teleconference calls.

The data analysis consists of three concurrent activities in this study: data reduction, data display, and conclusion drawing or verification [12]. Therefore, the data collected from this research was handled with data reduction to maintain the focus of this study, data display, and conclusion of verification as mentioned in this particular study.

\section{Result and Discussion}

In a conventional family, the husband is in charge of earning a living while the wife is in charge of taking care of the household; however, with the growth of opportunities for women to work, the family pattern immediately changes and emerges, which is known as career dualism. In terms of work-family conflict, most of our informants reveal that they were having a problem with the time management, because they have two different roles working together at the same time. For them to do the the task of work and responsibilities to finish their job and also at the same time helping their kids with the study at-home system.

With the work from home regulation, they also have to make sure that they and their kids have different gadgets to work with and also have the internet or other facilities to ensure the process of working or studying working well. The problem also arises when they also have other children who need their attention (like still having a baby). They also stated that with working from home, the amount of time spent to fulfill the demand from working is increasing than the 
previous time when they work from the office. This also leads to emotion-focused coping and problem-focused coping strategies to help them reduce the problem caused by that two domain of conflicts. One way to solve the problem is by conducting flexible working, because they also stated that during this pandemic time they still choose to work from home because they feel safe, also it's great for them to spend more time with their families.

Apperson (2002) showed that the intensity of the occurrence of WFC was greater in women than men because of women's involvement and time commitment to their responsibilities in household tasks, including taking care of their husbands and children, which could potentially lead to conflict [13]. This condition is supported by the role of women who naturally conceive and give birth to children so that the demands for the obligation to care for children become stronger than men. Research by Greenhaus and Beutell (1985) shows how women are placed in the challenge of managing family and work responsibilities[1].

According to Vinokur, Pierce and Burk (1999), for professional women who have relatively the same career status as their husbands, there is a traditional pattern in the distribution of childcare tasks and other family responsibilities that are considered detrimental to women's roles [14]. Furthermore, it is said that women have a greater responsibility in household matters than their husband.

Coping strategies such as family segmentation, social support especially from family or spouse, open communication, and positive work-family culture were chosen to be the coping strategies from this study. Another research-based on qualitative data described some approaches that people can use to shuffle between work and family life demands to be balanced. The term of flex style is believed to be the best way to handle the difficulties during this pandemic time.

It consists of how a person can manage emotions, actions, moods, and their thoughts to find a way of combining work and personal life that makes individuals feel good about their working life to manage work and family life as the best approach [15]. One of the solutions mentioned from one of the informants is by implementing family segmentation. The kind of segmentation described by the informants is by using open communication with other family at home to make an agreement and adjustment to divide their job and responsibilities at home when the other one has some work to finish with.

Social support from family, relatives, friends, and coworkers during this pandemic time was the instrument in coping with stressful situations both at home and at work. This coping strategy is also described as a critical problem-solving coping strategy. As reported by one of the informants: 'when facing work-family conflict at home, especially when having two different roles at the same time, getting the help from family especially from husband really help me when I am feeling stress and exhausted'. Receiving support from a partner or spouse is significantly crucial in coping with work and family conflicts.

Several informants mentioned that the problems occur when there is too much time for work, overlapping work, or when the time to work coincides with the time to prepare children for school from home or other family needs. If viewed from the informant as the primary resource person, the form of WFC owned by the informants is strain-based conflict. Strainbased conflict occurs because of the responsibility from one role affects the performance of another role [1].

Many informants reported pressure from the office, affecting emotional stability when at home or dealing with family members. It shows that in this study, the informant showed indications of work interfering with family, namely a condition where conflicts that occur in the office have an impact on life at home. Meanwhile, the informants also reported time-based 
conflicts due to current working conditions that take the same place as the role of the family, namely at home.

Family interfering with work-life is found in this study, but it is relatively manageable. The informants get help from other family members and household assistants for helping take care of the children when they are at work. Research informants also reported good husband support. The husbands of these informants allowed their wives to work and were willing to help their wives solve problems experienced, both for office problems and family problems.

Social support in dealing with the current coronavirus pandemic situation is significant in the human health dimension. Social support comes from close family, friends, coworkers, neighbors, and friends in activities. Social contact is crucial for physical and mental health. Research shows that social interaction and support can help minimize the level of stress, anxiety, isolation, depression, and improve self-control of normal life, well-being, and quality of life.

Meanwhile, a lack of social support has the opposite effect. The positive impact of good social support means that it directly impacts health and well-being because it creates comfort, security, and a sense of purpose in life. Social support can reduce various forms of stress, improve coping mechanisms and improve quality of life.

\section{Conclusion}

For women's employee, work and family are the two most important domains. With different work systems with more flexible time to juggle work and family roles, a healthy organization that aims to create a work-family friendly environment that harmonizes work, and family life, while still concerned about the organization's needs is thoroughly needed. The integration and flexibility of work and family include the development and promotion of workfamily friendly policies such as job flexibility and need-based support as the organizational strategic plans, especially during this pandemic time.

There is a general assumption that social support from work domain is related to workfamily conflict. Our findings found that getting help from team member or coworkers also help to deal with the difficulties. The reason because those colleagues may stand in for each other when the symptom of conflict appear by taking over some tasks to enable the other to do the family role, knowing that the other will return a favor if needed. Social support from a spouse related to time and strain-based conflict.

The forms of social support during the current Covid-19 pandemic are (1) appraisal support to solve problems or describe stressors, one of which is being a good listener, (2) tangible support, in the form of real assistance in solving problems, assistance can be in the form of food, masks or equipment needed medical assistance, (3) self-esteem support, support for a good selfview about themself, in the form of economic assistance and mental support, and (4) belonging support in the form of acceptance in one part or one group, in the form of no social isolation.

Recommendations have been proposed based on informants coping strategies such as family segmentation, social support, especially from family or spouse, open communication, and positive work-family culture. Given these results, future research needs to investigate how to achieve work-life balance with the help of social support, especially from family or work domain.

\section{References}

[1] Greenhaus, J. H., \& Beutell, N. J. (1985). Sources of conflict between work and family roles. Academy of Management Review, 10(1): 76-88. 
[2] Frone, M. R. (2003). Work-family balance. Handbook of occupational health psychology: 143-162.

[3] Kovacs, M. (2007) 'Stress and coping in the workplace', The Psychologist, 20(9): 548-550.

[4] Lazarus, R. (1998) The Life and Work of an Eminent Psychologist: Autobiography of Richard S. Lazarus, New York, Springer

[5] Monat, A., Lazarus, R. S. \& Reevy, G. (2007) Handbook on Stress and Coping, vol. 2 Praeger, Westport, CT.

[6] Folkman, S., \& Lazarus, R. S. (1980). An analysis of coping in a middle-aged community sample. Journal of Health and Social Behavior, 21: 219-239.

[7] Craver, C. S., Scheier, M. F. \& Weintraub, J. K. (1989) 'Assessing coping strategies: a theoretically based approach', Journal of Personality and Social Psychology, 56 (2); 267-283

[8] House, J. S. (1981). Work stress and social support. Reading, MA: Addison-Wesley

[9] Carlson, D. S., \& Perrewé, P. L. (1999). The role of social support in the stressor-strain relationship: An examination of work-family conflict. Journal of Management, 25: 513-540

[10] Thomas, L. T., \& Ganster, D. C. (1995). Impact of family-supportive work variables on work-family conflict and strain: A control perspective. Journal of Applied Psychology, 80, 6-15.

[11] Creswell, John W. (2009). Research Design: Qualitatif, Quantitative, and Mixed Methods Approaches. Third Edition (Terjemahan) 2013 Research Design: Pendekatan Kualitatif, Kuantitatif, dan Mixed. Yogyakarta: Pustaka Pelajar

[12] Miles, B. M., \& Hubermaan, M. (2009). Analisis data kualitatif. (Penerj. Tjeetjep Rohendi Rohidi) Jakarta: Universitas Indonesia Press. (Naskah asli diterbitkan tahun 1992)

[13] Apperson et al. (2002). "Women Managers and the Experience of Work-Family Conflict". American Journal of Undergraduate Research. Vol.1. No.3.

[14] Vinokur, A.D., Pierce, P.F., \& Burk, C.L. (1999). Work-family conflicts of women in the Air Force: their influence on mental health and functioning. Journal of Organizational Behavior, 20: 865-878.

[15] Kossek, E.E., Colquit, J.A., \& Noe, R.A. (2001). Caregiving desicions, well-being, and performance: The effect of place and provider as a function of dependent type and work-family climates. Academy of Management Journal, 44: 29-44. 